\title{
Hierarchical convergence of an implicit double- net algorithm for nonexpansive semigroups and variational inequality problems
}

\author{
Yonghong Yao ${ }^{1}$, Yeol Je Cho ${ }^{2^{*}}$ and Yeong-Cheng Liou ${ }^{3}$
}

\footnotetext{
* Correspondence: yjcho@gsnu.ac. $\mathrm{kr}$

${ }^{2}$ Department of Mathematics Education and the RINS, Gyeongsang National University, Chinju 660-701, Republic of Korea Full list of author information is available at the end of the article
}

\section{Abstract}

In this paper, we show the hierarchical convergence of the following implicit doublenet algorithm:

$$
x_{s, t}=s\left[t f\left(x_{s, t}\right)+(1-t)\left(x_{s, t}-\mu A x_{s, t}\right)\right]+(1-s) \frac{1}{\lambda_{s}} \int_{0}^{\lambda_{s}} T(v) x_{s, t} d v, \quad \forall s, t \in(0,1),
$$

where $f$ is a $\rho$-contraction on a real Hilbert space $H, A: H \rightarrow H$ is an $\alpha$-inverse strongly monotone mapping and $S=\{T(S)\}_{S} \geq 0: H \rightarrow H$ is a nonexpansive semigroup with the common fixed points set $\operatorname{Fix}(S) \neq \varnothing$, where $\operatorname{Fix}(S)$ denotes the set of fixed points of the mapping $S$, and, for each fixed $t \in(0,1)$, the net $\left\{x_{s, t}\right\}$ converges in norm as $s \rightarrow 0$ to a common fixed point $x_{t} \in \operatorname{Fix}(S)$ of $\{T(s)\}_{s} \geq 0$ and, as $t \rightarrow 0$, the net $\left\{X_{t}\right\}$ converges in norm to the solution $x^{*}$ of the following variational inequality:

$$
\left\{\begin{array}{l}
x^{*} \in \operatorname{Fix}(S) \\
\left\langle A x^{*}, x-x^{*}\right\rangle \geq 0, \forall x \in \operatorname{Fix}(S) .
\end{array}\right.
$$

MSC(2000): 49J40; 47J20; 47H09; 65J15.

Keywords: fixed point, variational inequality, double-net algorithm, hierarchical convergence, Hilbert space

\section{Introduction}

In nonlinear analysis, a common approach to solving a problem with multiple solutions is to replace it by a family of perturbed problems admitting a unique solution and to obtain a particular solution as the limit of these perturbed solutions when the perturbation vanishes.

In this paper, we introduce a more general approach which consists in finding a particular part of the solution set of a given fixed point problem, i.e., fixed points which solve a variational inequality. More precisely, the goal of this paper is to present a method for finding hierarchically a fixed point of a nonexpansive semigroup $S=\{T(s)\}_{s}$ $\geq 0$ with respect to another monotone operator $A$, namely,

Find $x^{*} \in \operatorname{Fix}(S)$ such that

$$
\left\langle A x^{*}, x-x^{*}\right\rangle \geq 0, \quad \forall x \in \operatorname{Fix}(S) .
$$

\section{Springer}

(c) 2011 Yao et al; licensee Springer. This is an Open Access article distributed under the terms of the Creative Commons Attribution License (http://creativecommons.org/licenses/by/2.0), which permits unrestricted use, distribution, and reproduction in any medium, provided the original work is properly cited. 
This is an interesting topic due to the fact that it is closely related to convex programming problems. For the related works, refer to [1-19].

This paper is devoted to solve the problem (1.1). For this purpose, we propose a double-net algorithm which generates a net $\left\{x_{s, t}\right\}$ and prove that the net $\left\{x_{s, t}\right\}$ hierarchically converges to the solution of the problem (1.1), that is, for each fixed $t \in(0,1)$, the net $\left\{x_{s, t}\right\}$ converges in norm as $s \rightarrow 0$ to a common fixed point $x_{t} \in \operatorname{Fix}(S)$ of the nonexpansive semigroup $\{T(s)\}_{s} \geq 0$ and, as $t \rightarrow 0$, the net $\left\{x_{t}\right\}$ converges in norm to the unique solution $x^{*}$ of the problem (1.1).

\section{Preliminaries}

Let $H$ be a real Hilbert space with inner product $\langle\cdot, \cdot\rangle$ and norm $\|\cdot\|$, respectively. Recall a mapping $f: H \rightarrow H$ is called a contraction if there exists $\rho \in[0,1)$ such that

$$
\|f(x)-f(y)\| \leq \rho\|x-y\|, \quad \forall x, y \in H .
$$

A mapping $T: C \rightarrow C$ is said to be nonexpansive if

$$
\|T x-T y\| \leq\|x-y\|, \quad \forall x, y \in H .
$$

Denote the set of fixed points of the mapping $T$ by $F i x(T)$.

Recall also that a family $S:=\{T(s)\}_{s} \geq 0$ of mappings of $H$ into itself is called a nonexpansive semigroup if it satisfies the following conditions:

(S1) $T(0) x=x$ for all $x \in H$;

(S2) $T(s+t)=T(s) T(t)$ for all $s, t \geq 0$;

(S3) $\|T(s) x-T(s) y\| \leq\|x-y\|$ for all $x, y \in H$ and $s \geq 0$;

(S4) for all $x \in H, s \rightarrow T(s) x$ is continuous.

We denote by $F i x(T(s))$ the set of fixed points of $T(s)$ and by $\operatorname{Fix}(S)$ the set of all common fixed points of $S$, i.e., $\operatorname{Fix}(S)=\mathrm{n}_{s} \geq 0 \operatorname{Fix}(T(s))$. It is known that $\operatorname{Fix}(S)$ is closed and convex ([20], Lemma 1).

A mapping $A$ of $H$ into itself is said to be monotone if

$$
\langle A u-A v, u-v\rangle \geq 0, \quad \forall u, v \in H,
$$

and $A: C \rightarrow H$ is said to be $\alpha$-inverse strongly monotone if there exists a positive real number $\alpha$ such that

$$
\langle A u-A v, u-v\rangle \geq \alpha\|A u-A v\|^{2}, \quad \forall u, v \in H .
$$

It is obvious that any $\alpha$-inverse strongly monotone mapping $A$ is monotone and $\frac{1}{\alpha}$-Lipschitz continuous.

Now, we introduce some lemmas for our main results in this paper.

Lemma 2.1. [21] Let $H$ be a real Hilbert space. Let the mapping $A: H \rightarrow H$ be $\alpha$ inverse strongly monotone and $\mu>0$ be a constant. Then, we have

$$
\|(I-\mu A) x-(I-\mu A) y\|^{2} \leq\|x-y\|^{2}+\mu(\mu-2 \alpha)\|A x-A y\|^{2}, \quad \forall x, y \in H .
$$

In particular, if $0 \leq \mu \leq 2 \alpha$, then $I-\mu A$ is nonexpansive.

Lemma 2.2. [22] Let $C$ be a nonempty bounded closed convex subset of a Hilbert space $H$ and $\{T(s)\}_{s} \geq 0$ be a nonexpansive semigroup on $C$. Then, for all $h \geq 0$, 


$$
\lim _{t \rightarrow \infty} \sup _{x \in C}\left\|\frac{1}{t} \int_{0}^{t} T(s) x d s-T(h) \frac{1}{t} \int_{0}^{t} T(s) x d s\right\|=0 .
$$

Lemma 2.3. [23] (Demiclosedness Principle for Nonexpansive Mappings) Let $C$ be a nonempty closed convex subset of a real Hilbert space $H$ and $T: C \rightarrow C$ be a nonexpansive mapping with Fix $(T) \neq \varnothing$. If $\left\{x_{n}\right\}$ is a sequence in $C$ converging weakly to a point $x \in C$ and $\left\{(I-T) x_{n}\right\}$ converges strongly to a point $y \in C$, then $(I-T) x=y$. In particular, if $y=0$, then $x \in$ Fix $(T)$.

Lemma 2.4. Let $H$ be a real Hilbert space. Let $f: H \rightarrow H$ be a $\rho$-contraction with coefficient $\rho \in[0,1)$ and $A: H \rightarrow H$ be an $\alpha$-inverse strongly monotone mapping. Let $\mu$ $\in(0,2 \alpha)$ and $t \in(0,1)$. Then, the variational inequality

$$
\left\{\begin{array}{l}
x^{*} \in \operatorname{Fix}(S) ; \\
\left\langle t f(z)+(1-t)(I-\mu A) z-z, x^{*}-z\right\rangle \geq 0, \quad \forall z \in \operatorname{Fix}(S),
\end{array}\right.
$$

is equivalent to its dual variational inequality

$$
\left\{\begin{array}{l}
x^{*} \in \operatorname{Fix}(S) \\
\left\langle t f\left(x^{*}\right)+(1-t)(I-\mu A) x^{*}-x^{*}, x^{*}-z\right\rangle \geq 0, \quad \forall z \in \operatorname{Fix}(S) .
\end{array}\right.
$$

Proof. Assume that $x^{*} \in \operatorname{Fix}(S)$ solves the problem (2.1). For all $y \in \operatorname{Fix}(S)$, set

$$
x=x^{*}+s\left(y-x^{*}\right) \in \operatorname{Fix}(S), \quad \forall s \in(0,1) .
$$

We note that

$$
\left\langle t f(x)+(1-t)(I-\mu A) x-x, x^{*}-x\right\rangle \geq 0 .
$$

Hence, we have

$$
\left\langle t f\left(x^{*}+s\left(y-x^{*}\right)\right)+(1-t)(I-\mu A)\left(x^{*}+s\left(y-x^{*}\right)\right)-x^{*}-s\left(y-x^{*}\right), s\left(x^{*}-y\right)\right\rangle \geq 0,
$$

which implies that

$$
\left\langle t f\left(x^{*}+s\left(y-x^{*}\right)\right)+(1-t)(I-\mu A)\left(x^{*}+s\left(y-x^{*}\right)\right)-x^{*}-s\left(y-x^{*}\right), x^{*}-y\right\rangle \geq 0 .
$$

Letting $s \rightarrow 0$, we have

$$
\left\langle t f\left(x^{*}\right)+(1-t)(I-\mu A)\left(x^{*}\right)-x^{*}, x^{*}-y\right\rangle \geq 0,
$$

which implies the point $x^{*} \in F i x(S)$ is a solution of the problem (2.2).

Conversely, assume that the point $x^{*} \in F i x(S)$ solves the problem (2.2). Then, we have

$$
\left\langle t f\left(x^{*}\right)+(1-t)(I-\mu A) x^{*}-x^{*}, x^{*}-z\right\rangle \geq 0 .
$$

Noting that $I-f$ and $A$ are monotone, we have

$$
\left\langle(I-f) z-(I-f) x^{*}, z-x^{*}\right\rangle \geq 0
$$

and

$$
\left\langle A z-A x^{*}, z-x^{*}\right\rangle \geq 0 .
$$


Thus, it follows that

$$
t\left\langle(I-f) z-(I-f) x^{*}, z-x^{*}\right\rangle+(1-t) \mu\left\langle A z-A x^{*}, z-x^{*}\right\rangle \geq 0,
$$

which implies that

$$
\begin{aligned}
\langle t f(z)+(1-t)(I & \left.-\mu A) z-z, x^{*}-z\right\rangle \\
& \geq\left\langle t f\left(x^{*}\right)+(1-t)(I-\mu A) x^{*}-x^{*}, x^{*}-z\right\rangle \\
& \geq 0
\end{aligned}
$$

This implies that the point $x^{*} \in \operatorname{Fix}(S)$ solves the problem (2.1). This completes the proof. $\square$

\section{Main results}

In this section, we first introduce our double-net algorithm and then prove a strong convergence theorem for this algorithm.

Throughout, we assume that

(C1) $H$ is a real Hilbert space;

(C2) $f: H \rightarrow H$ is a $\rho$-contraction with coefficient $\rho \in[0,1), A: H \rightarrow H$ is an $\alpha$ inverse strongly monotone mapping, and $S=\{T(s)\}_{s} \geq 0: H \rightarrow H$ is a nonexpansive semigroup with $\operatorname{Fix}(S) \neq \varnothing$;

(C3) the solution set $\Omega$ of the problem (1.1) is nonempty;

(C4) $\mu \in(0,2 \alpha)$ is a constant, and $\left\{\lambda_{s}\right\}_{0<s<1}$ is a continuous net of positive real numbers satisfying $\lim _{s \rightarrow 0} \lambda_{s}=+\infty$.

For any $s, t \in(0,1)$, we define the following mapping

$$
x \mapsto W_{s, t} x:=s[t f(x)+(1-t)(x-\mu A x)]+(1-s) \frac{1}{\lambda_{s}} \int_{0}^{\lambda_{s}} T(v) x d \nu .
$$

We note that the mapping $W_{s, t}$ is a contraction. In fact, we have

$$
\begin{aligned}
\left\|W_{s, t} x-W_{s, t} y\right\|= & \| s[t f(x)+(1-t)(x-\mu A x)]+(1-s) \frac{1}{\lambda_{s}} \int_{0}^{\lambda_{s}} T(v) x d v \\
& \quad-s[t f(y)+(1-t)(y-\mu A y)]-(1-s) \frac{1}{\lambda_{s}} \int_{0}^{\lambda_{s}} T(v) y d v\|\| \\
\leq & s t\|f(x)-f(y)\|+s(1-t)\|(x-\mu A x)-(y-\mu A y)\| \\
& \quad+(1-s)\left\|\frac{1}{\lambda_{s}} \int_{0}^{\lambda_{s}}(T(v) x-T(v) y) d v\right\| \\
\leq & s t \rho\|x-y\|+s(1-t)\|x-y\|+(1-s)\|x-y\| \\
= & {[1-(1-\rho) s t]\|x-y\|, }
\end{aligned}
$$

which implies that $W_{s, t}$ is a contraction. Hence, by Banach's Contraction Principle, $W_{s, t}$ has a unique fixed point, which is denoted $x_{s, t} \in H$, that is, $x_{s, t}$ is the unique solution in $H$ of the fixed point equation

$$
\begin{aligned}
& x_{s, t}=s[\left.t f\left(x_{s, t}\right)+(1-t)\left(x_{s, t}-\mu A x_{s, t}\right)\right] \\
&+(1-s) \frac{1}{\lambda_{s}} \int_{0}^{\lambda_{s}} T(v) x_{s, t} d v, \quad \forall s, t \in(0,1) .
\end{aligned}
$$

Now, we give some lemmas for our main result.

Lemma 3.1. For each fixed $t \in(0,1)$, the net $\left\{x_{s, t}\right\}$ defined by (3.1) is bounded. 
Proof. Taking any $z \in F i x(S)$, since $I-\mu A$ is nonexpansive (by Lemma 2.1), it follows from (3.1) that

$$
\begin{aligned}
& \left\|x_{s, t}-z\right\| \\
= & \left\|s\left[t f\left(x_{s, t}\right)+(1-t)(I-\mu A) x_{s, t}\right]+(1-s) \frac{1}{\lambda_{s}} \int_{0}^{\lambda_{s}} T(v) x_{s, t} d v-z\right\| \\
\leq & s\left\|t f\left(x_{s, t}\right)+(1-t)(I-\mu A) x_{s, t}-z\right\|+(1-s)\left\|\frac{1}{\lambda_{s}} \int_{0}^{\lambda_{s}} T(v) x_{s, t} d v-z\right\| \\
\leq & s\left[t\left\|f\left(x_{s, t}\right)-f(z)\right\|+t\|f(z)-z\|+(1-t)\left\|(I-\mu A) x_{s, t}-(I-\mu A) z\right\|\right. \\
& +(1-t)\|(I-\mu A) z-z\|]+(1-s)\left\|x_{s, t}-z\right\| \\
\leq & s\left[t \rho\left\|x_{s, t}-z\right\|+t\|f(z)-z\|+(1-t)\left\|x_{s, t}-z\right\|+(1-t) \mu\|A z\|\right] \\
& +(1-s)\left\|x_{s, t}-z\right\| \\
= & {[1-(1-\rho) s t]\left\|x_{s, t}-z\right\|+s t \mid\|f(z)-z\|+s(1-t) \mu\|A z\| . }
\end{aligned}
$$

This implies that

$$
\begin{aligned}
\left\|x_{s, t}-z\right\| & \leq \frac{1}{(1-\rho) t}(t|| f(z)-z\|+(1-t) \mu\| A z||) \\
& \leq \frac{1}{(1-\rho) t} \max \{\|f(z)-z\|, \mu\|A z\|\} .
\end{aligned}
$$

Thus, it follows that, for each fixed $t \in(0,1),\left\{x_{s, t}\right\}$ is bounded and so are the nets $\{f$ $\left.\left(x_{s, t}\right)\right\}$ and $\left\{(I-\mu A) x_{s, t}\right\}$. This completes the proof. $\square$

Lemma 3.2. $x_{s, t} \rightarrow x_{t} \in \operatorname{Fix}(S)$ as $s \rightarrow 0$.

Proof. For each fixed $t \in(0,1)$, we set $R_{t}:=\frac{1}{(1-\rho) t} \max \{\|f(z)-z\|, \mu\|A z\|\}$. It is clear that, for each fixed $t \in(0,1),\left\{x_{s, t}\right\} \subset B\left(p, R_{t}\right)$, where $B\left(p, R_{t}\right)$ denotes a closed ball with the center $p$ and radius $R_{t}$. Notice that

$$
\left\|\frac{1}{\lambda_{s}} \int_{0}^{\lambda_{s}} T(v) x_{s, t} d v-p\right\| \leq\left\|x_{s, t}-p\right\| \leq R_{t} .
$$

Moreover, we observe that if $x \in B\left(p, R_{t}\right)$, then

$$
\|T(s) x-p\| \leq\|T(s) x-T(s) p\| \leq\|x-p\| \leq R_{t}
$$

that is, $B\left(p, R_{t}\right)$ is $T(s)$-invariant for all $s \in(0,1)$. From (3.1), it follows that

$$
\begin{aligned}
\left\|T(\tau) x_{s, t}-x_{s, t}\right\| \leq & \left\|(\tau) x_{s, t}-T(\tau) \frac{1}{\lambda_{s}} \int_{0}^{\lambda_{s}} T(v) x_{s, t} d v\right\| \\
& +\left\|T(\tau) \frac{1}{\lambda_{s}} \int_{0}^{\lambda_{s}} T(v) x_{s, t} d v-\frac{1}{\lambda_{s}} \int_{0}^{\lambda_{s}} T(v) x_{s, t} d v\right\| \\
& +\left\|\frac{1}{\lambda_{s}} \int_{0}^{\lambda_{s}} T(v) X_{s, t} d v-x_{s, t}\right\| \\
\leq & \left\|T(\tau) \frac{1}{\lambda_{s}} \int_{0}^{\lambda_{s}} T(v) x_{s, t} d v-\frac{1}{\lambda_{s}} \int_{0}^{\lambda_{s}} T(v) x_{s, t} d v\right\| \\
& +2\left\|x_{s_{s, t}}-\frac{1}{\lambda_{s}} \int_{0}^{\lambda_{s}} T(v) X_{s, t} d v\right\| \\
\leq & 2 s\left\|t f\left(x_{s, t}\right)+(1-t)\left(x_{s, t}-\mu A x_{s, t}\right)-\frac{1}{\lambda_{s}} \int_{0}^{\lambda_{s}} T(v) x_{s, t} d v\right\| \\
& +\left\|T(\tau) \frac{1}{\lambda_{s}} \int_{0}^{\lambda_{s}} T(v) x_{s, t} d v-\frac{1}{\lambda_{s}} \int_{0}^{\lambda_{s}} T(v) x_{s, t} d v\right\| .
\end{aligned}
$$


By Lemma 2.2, for all $0 \leq \tau<\infty$ and fixed $t \in(0,1)$, we deduce

$$
\lim _{s \rightarrow 0}\left\|T(\tau) x_{s, t}-x_{s, t}\right\|=0
$$

Next, we show that, for each fixed $t \in(0,1)$, the net $\left\{x_{s, t}\right\}$ is relatively norm-compact as $s \rightarrow 0$. In fact, from Lemma 2.1, it follows that

$$
\left\|x_{s, t}-\mu A x_{s, t}-(z-\mu A z)\right\|^{2} \leq\left\|x_{s, t}-z\right\|^{2}+\mu(\mu-2 \alpha)\left\|A x_{s, t}-A z\right\|^{2} .
$$

By (3.1), we have

$$
\begin{aligned}
& \left\|x_{s, t}-z\right\|^{2} \\
=\quad & s t\left\langle f\left(x_{s, t}\right)-f(z), x_{s, t}-z\right\rangle+s t\left\langle f(z)-z, x_{s, t}-z\right\rangle \\
& +s(1-t)\left\langle(I-\mu A) x_{s, t}-(I-\mu A) z, x_{s, t}-z\right\rangle \\
& +s(1-t)\left\langle(I-\mu A) z-z, x_{s, t}-z\right\rangle \\
& +(1-s)\left\langle\frac{1}{\lambda_{s}} \int_{0}^{\lambda_{s}} T(v) X_{s, t} d v-z, x_{s, t}-z\right\rangle \\
\leq \quad & s t|| f\left(x_{s, t}\right)-f(z)\|\| x_{s, t}-z \|+s t\left\langle f(z)-z, x_{s, t}-z\right\rangle \\
& +s(1-t)\left\|(I-\mu A) x_{s, t}-(I-\mu A) z\right\|\left\|x_{s, t}-z\right\|-s(1-t) \mu\left\langle A z, x_{s, t}-z\right\rangle \\
& +(1-s)\left\|\frac{1}{\lambda_{s}} \int_{0}^{\lambda_{s}} T(v) X_{s, t} d v-z\right\|\left\|x_{s, t}-z\right\| \\
\leq \quad & s t \rho\left\|x_{s, t}-z\right\|^{2}+s t\left\langle f(z)-z, x_{s, t}-z\right\rangle-s(1-t) \mu\left\langle A z, x_{s, t}-z\right\rangle \\
& +s(1-t)\left\|(I-\mu A) x_{s, t}-(I-\mu A) z\right\|\left\|x_{s, t}-z\right\|+(1-s)\left\|x_{s, t}-z\right\|^{2} \\
\leq \quad & s t \rho\left\|x_{s, t}-z\right\|^{2}+s t\left\langle f(z)-z, x_{s, t}-z\right\rangle-s(1-t) \mu\left\langle A z, x_{s, t}-z\right\rangle \\
& +\frac{s(1-t)}{2}\left(\left\|(I-\mu A) x_{s, t}-(I-\mu A) z\right\|^{2}+\left\|x_{s, t}-z\right\|^{2}\right)+(1-s)\left\|x_{s, t}-z\right\|^{2} .
\end{aligned}
$$

This together with (3.3) imply that

$$
\begin{aligned}
& \left\|x_{s, t}-z\right\|^{2} \\
\leq \quad & s t \rho\left\|x_{s, t}-z\right\|^{2}+s t\left\langle f(z)-z, x_{s, t}-z\right\rangle-s(1-t) \mu\left\langle A z, x_{s, t}-z\right\rangle \\
& +\frac{s(1-t)}{2}\left(\left\|x_{s, t}-z\right\|^{2}+\mu(\mu-2 \alpha)\left\|A x_{s, t}-A z\right\|^{2}+\left\|x_{s, t}-z\right\|^{2}\right)+(1-s)\left\|x_{s, t}-z\right\|^{2} \\
\leq \quad & {[1-(1-\rho) s t]\left\|x_{s, t}-z\right\|^{2}+s t\left\langle f(z)-z, x_{s, t}-z\right\rangle } \\
& -s(1-t) \mu\left\langle A z, x_{s, t}-z\right\rangle,
\end{aligned}
$$

which implies that

$$
\begin{aligned}
& \left\|x_{s, t}-z\right\|^{2} \\
\leq & \frac{1}{(1-\rho) t}\left\langle t f(z)+(1-t)(I-\mu A) z-z, x_{s, t}-z\right\rangle, \quad \forall z \in \operatorname{Fix}(S) .
\end{aligned}
$$

Assume that $\left\{s_{n}\right\} \subset(0,1)$ is such that $s_{n} \rightarrow 0$ as $n \rightarrow \infty$. By (3.4), we obtain immediately that

$$
\begin{aligned}
& \left\|x_{s_{n}, t}-z\right\|^{2} \\
\leq & \frac{1}{(1-\rho) t}\left\langle t f(z)+(1-t)(I-\mu A) z-z, x_{s_{n}, t}-z\right\rangle, \quad \forall z \in \operatorname{Fix}(S) .
\end{aligned}
$$

Since $\left\{x_{s_{n}, t}\right\}$ is bounded, without loss of generality, we may assume that, as $s_{n} \rightarrow 0$, $\left\{x_{s_{n}, t}\right\}$ converges weakly to a point $x_{t}$. From (3.2) and Lemma 2.3, we get $x_{t} \in \operatorname{Fix}(S)$. 
Further, if we substitute $x_{t}$ for $z$ in (3.5), then it follows that

$$
\left\|x_{s_{n}, t}-x_{t}\right\|^{2} \leq \frac{1}{(1-\rho) t}\left\langle t f\left(x_{t}\right)+(1-t)(I-\mu A) x_{t}-x_{t}, x_{s_{n}, t}-x_{t}\right\rangle .
$$

Therefore, the weak convergence of $\left\{x_{s_{n}, t}\right\}$ to $x_{t}$ actually implies that $x_{s_{n}, t} \rightarrow x_{t}$ strongly. This has proved the relative norm-compactness of the net $\left\{x_{s}, t\right\}$ as $s \rightarrow 0$.

Now, if we take the limit as $n \rightarrow \infty$ in (3.5), we have

$$
\begin{aligned}
& \left\|x_{t}-z\right\|^{2} \\
\leq & \frac{1}{(1-\rho) t}\left\langle t f(z)+(1-t)(I-\mu A) z-z, x_{t}-z\right\rangle, \quad \forall z \in \operatorname{Fix}(S) .
\end{aligned}
$$

In particular, $x_{t}$ solves the following variational inequality:

$$
\left\{\begin{array}{l}
x_{t} \in \operatorname{Fix}(S) \\
\left\langle t f(z)+(1-t)(I-\mu A) z-z, x_{t}-z\right\rangle \geq 0, \quad \forall z \in \operatorname{Fix}(S),
\end{array}\right.
$$

or the equivalent dual variational inequality (see Lemma 2.4):

$$
\left\{\begin{array}{l}
x_{t} \in \operatorname{Fix}(S) \\
\left\langle t f\left(x_{t}\right)+(1-t)(I-\mu A) x_{t}-x_{t}, x_{t}-z\right\rangle \geq 0, \quad \forall z \in \operatorname{Fix}(S) .
\end{array}\right.
$$

Notice that (3.6) is equivalent to the fact that $x_{t}=P_{F i x(S)}(t f+(1-t)(I-\mu A)) x_{t}$, that is, $x_{t}$ is the unique element in $\operatorname{Fix}(S)$ of the contraction $P_{\text {Fix }(S)}(t f+(1-t)(I-\mu A))$. Clearly, it is sufficient to conclude that the entire net $\left\{x_{s, t}\right\}$ converges in norm to $x_{t} \in \operatorname{Fix}(S)$ as $s$ $\rightarrow 0$. This completes the proof.

Lemma 3.3. The net $\left\{x_{t}\right\}$ is bounded.

Proof. In (3.6), if we take any $y \in \Omega$, then we have

$$
\left\langle t f\left(x_{t}\right)+(1-t)(I-\mu A) x_{t}-x_{t}, x_{t}-\gamma\right\rangle \geq 0 .
$$

By virtue of the monotonicity of $A$ and the fact that $y \in \Omega$, we have

$$
\left\langle(I-\mu A) x_{t}-x_{t}, x_{t}-y\right\rangle \leq\left\langle(I-\mu A) y-y, x_{t}-y\right\rangle \leq 0 .
$$

Thus, it follows from (3.7) and (3.8) that

$$
\left\langle f\left(x_{t}\right)-x_{t}, x_{t}-y\right\rangle \geq 0, \quad \forall y \in \Omega
$$

and hence

$$
\begin{aligned}
\left\|x_{t}-y\right\|^{2} \leq & \left\langle x_{t}-y, x_{t}-y\right\rangle+\left\langle f\left(x_{t}\right)-x_{t}, x_{t}-y\right\rangle \\
& =\left\langle f\left(x_{t}\right)-f(y), x_{t}-y\right\rangle+\left\langle f(y)-y, x_{t}-\gamma\right\rangle \\
\leq & \rho\left\|x_{t}-\gamma\right\|^{2}+\left\langle f(\gamma)-\gamma, x_{t}-\gamma\right\rangle .
\end{aligned}
$$

Therefore, we have

$$
\left\|x_{t}-y\right\|^{2} \leq \frac{1}{1-\rho}\left\langle f(y)-y, x_{t}-y\right\rangle, \quad \forall y \in \Omega .
$$

In particular,

$$
\left\|x_{t}-y\right\| \leq \frac{1}{1-\rho}\|f(\gamma)-y\|, \quad \forall t \in(0,1),
$$


which implies that $\left\{x_{t}\right\}$ is bounded. This completes the proof. $\square$

Lemma 3.4. If the net $\left\{x_{t}\right\}$ converges in norm to a point $x^{*} \in \Omega$, then the point solves the variational inequality

$$
\left\langle(I-f) x^{*}, x-x^{*}\right\rangle \geq 0, \quad \forall x \in \Omega .
$$

Proof. First, we note that the solution of the variational inequality (3.11) is unique.

Next, we prove that $\omega_{w}\left(x_{t}\right) \subset \Omega$, that is, if $\left(t_{n}\right)$ is a null sequence in $(0,1)$ such that $x_{t_{n}} \rightarrow x^{\prime}$ weakly as $n \rightarrow \infty$, then $x^{\prime} \in \Omega$. To see this, we use (3.6) to get

$$
\left\langle\mu A x_{t}, z-x_{t}\right\rangle \geq \frac{t}{1-t}\left\langle(I-f) x_{t}, x_{t}-z\right\rangle, \quad \forall z \in \operatorname{Fix}(S) .
$$

However, since $A$ is monotone, we have

$$
\left\langle A z, z-x_{t}\right\rangle \geq\left\langle A x_{t}, z-x_{t}\right\rangle
$$

Combining the last two relations yields that

$$
\left\langle\mu A z, z-x_{t}\right\rangle \geq \frac{t}{1-t}\left\langle(I-f) x_{t}, x_{t}-z\right\rangle, \quad \forall z \in \operatorname{Fix}(S) .
$$

Letting $t=t_{n} \rightarrow 0$ as $n \rightarrow \infty$ in (3.12), we get

$$
\left\langle A z, z-x^{\prime}\right\rangle \geq 0, \quad \forall z \in \operatorname{Fix}(S),
$$

which is equivalent to its dual variational inequality

$$
\left\langle A x^{\prime}, z-x^{\prime}\right\rangle \geq 0, \quad \forall z \in \operatorname{Fix}(S) .
$$

That is, $x^{\prime}$ is a solution of the problem (1.1) and hence $x^{\prime} \in \Omega$.

Finally, we prove that $x^{\prime}=x^{*}$, the unique solution of the variational inequality (3.11). In fact, by (3.10), we have

$$
\left\|x_{t_{n}}-x^{\prime}\right\|^{2} \leq \frac{1}{1-\rho}\left\langle f\left(x^{\prime}\right)-x^{\prime}, x_{t_{n}}-x^{\prime}\right\rangle, \quad \forall x^{\prime} \in \Omega .
$$

Therefore, the weak convergence to $x^{\prime}$ of $\left\{x_{t_{n}}\right\}$ implies that $x_{t_{n}} \rightarrow x^{\prime}$ in norm. Thus, if we let $t=t_{n} \rightarrow 0$ in (3.10), then we have

$$
\left\langle f\left(x^{\prime}\right)-x^{\prime}, y-x^{\prime}\right\rangle \leq 0, \quad \forall y \in \Omega,
$$

which implies that $x^{\prime} \in \Omega$ solves the problem (3.11). By the uniqueness of the solution, we have $x^{\prime}=x^{*}$ and it is sufficient to guarantee that $x_{t} \rightarrow x^{*}$ in norm as $t \rightarrow 0$. This completes the proof.

Thus, by the above lemmas, we can obtain immediately the following theorem.

Theorem 3.5. For each $(s, t) \in(0,1) \times(0,1)$, let $\left\{x_{s, t}\right\}$ be a double-net algorithm defined implicitly by (3.1). Then, the net $\left\{x_{s, t}\right\}$ hierarchically converges to the unique solution $x^{*}$ of the hierarchical fixed point problem and the variational inequality problem (1.1), that is, for each fixed $t \in(0,1)$, the net $\left\{x_{s, t}\right\}$ converges in norm as $s \rightarrow 0$ to a common fixed point $x_{t} \in \operatorname{Fix}(S)$ of the nonexpansive semigroup $\{T(s)\}_{s} \geq 0$. Moreover, as $t \rightarrow 0$, the net $\left\{x_{t}\right\}$ converges in norm to the unique solution $x^{*} \in \Omega$ and the point $x^{*}$ 
also solves the following variational inequality.

$$
\left\{\begin{array}{l}
x^{*} \in \Omega \\
\left\langle(I-f) x^{*}, x-x^{*}\right\rangle \geq 0, \quad \forall x \in \Omega .
\end{array}\right.
$$

\section{Acknowledgements}

Yonghong Yao was supported in part by Colleges and Universities Science and Technology Development Foundation (20091003) of Tianjin and NSFC 11071279. Yeol Je Cho was supported by the Korea Research Foundation Grant funded by the Korean Government (KRF-2008-313-C00050). Yeong-Cheng Liou was supported in part by NSC 99-2221E-230-006.

\section{Author details}

${ }^{1}$ Department of Mathematics, Tianjin Polytechnic University, Tianjin 300160, People's Republic of China ${ }^{2}$ Department of Mathematics Education and the RINS, Gyeongsang National University, Chinju 660-701, Republic of Korea ${ }^{3}$ Department of Information Management, Cheng Shiu University, Kaohsiung 833, Taiwan

\section{Authors' contributions}

All authors read and approved the final manuscript.

\section{Competing interests}

The authors declare that they have no competing interests.

Received: 3 November 2010 Accepted: 20 December 2011 Published: 20 December 2011

\section{References}

1. Moudafi, A, Mainge, PE: Towards viscosity approximations of hierarchical fixed-point problems. Fixed Point Theory Appl 1-10 (2006). Article ID 95453

2. Moudafi, A: Krasnoselski-Mann iteration for hierarchical fixed-point problems. Inverse Problems. 23, 1635-1640 (2007). doi:10.1088/0266-5611/23/4/015

3. Mainge, PE, Moudafi, A: Strong convergence of an iterative method for hierarchical fixed-point problems. Pacific J Optim. 3, 529-538 (2007)

4. Yao, Y, Liou, YC: Weak and strong convergence of Krasnoselski-Mann iteration for hierarchical fixed point problems. Inverse Problems 24(1):8 (2008). 015015

5. Cianciaruso, F, Marino, G, Muglia, L, Yao, Y: On a two-step algorithm for hierarchical fixed Point problems and variational inequalities. J Inequal Appl 13 (2009). Article ID 208692 doi:10.1155/2009/208692

6. Cianciaruso, F, Colao, V, Muglia, L, Xu, HK: On an implicit hierarchical fixed point approach to variational inequalities. Bull Aust Math Soc. 80, 117-124 (2009). doi:10.1017/S0004972709000082

7. Marino, G, Colao, V, Muglia, L, Yao, Y: Krasnoselski-Mann iteration for hierarchical fixed points and equilibrium problem. Bull Aust Math Soc. 79, 187-200 (2009). doi:10.1017/S000497270800107X

8. Lu, X, Xu, HK, Yin, X: Hybrid methods for a class of monotone variational inequalities. Nonlinear Anal. 71, 1032-1041 (2009). doi:10.1016/j.na.2008.11.067

9. Yao, Y, Chen, $R, X u, H K$ : Schemes for finding minimum-norm solutions of variational inequalities. Nonlinear Anal. 72 3447-3456 (2010). doi:10.1016/j.na.2009.12.029

10. Yao, Y, Liou, YC, Marino, G: Two-step iterative algorithms for hierarchical fixed point problems and variational inequality problems. J Appl Math Comput. 31, 433-445 (2009). doi:10.1007/s12190-008-0222-5

11. Yao, Y, Cho, YJ, Liou, YC: Iterative algorithms for hierarchical fixed points problems and variational inequalities. Math Comput Model. 52, 1697-1705 (2010). doi:10.1016/j.mcm.2010.06.038

12. Xu, HK: Viscosity method for hierarchical fixed point approach to variational inequalities. Taiwan J Math. 14, 463-478 (2010)

13. Colao, V, Marino, G, Muglia, L: Viscosity methods for common solutions for equilibrium and hierarchical fixed point problems. Optim (in press). doi:10.1080/02331930903524688

14. Ceng, LC, Petrusel, A: Krasnoselski-Mann iterations for hierarchical fixed point problems for a finite family of nonself mappings in Banach spaces. J Optim Theory Appl. doi:10.1007/s10957-010-9679-0

15. Cabot, A: Proximal point algorithm controlled by a slowly vanishing term: applications to hierarchical minimization. SIAM J Optim. 15, 555-572 (2005). doi:10.1137/S105262340343467X

16. Luo, ZQ, Pang, JS, Ralph, D: Mathematical Programs with Equilibrium Constraints. Cambridge University Press, Cambridge (1996)

17. Solodov, M: An explicit descent method for bilevel convex optimization. J Convex Anal. 14, 227-237 (2007)

18. Yamada, I, Ogura, N: Hybrid steepest descent method for the variational inequality problem over the fixed point set of certain quasi-nonexpansive mappings. Numer Funct Anal Optim. 25, 619-655 (2004)

19. Guo, G, Wang, S, Cho, YJ: Strong convergence algorithms for hierarchical fixed point problems and variational inequalities. J Appl Math Vol 17 (2011). Article ID 164978, doi:10.1155/2011/164978

20. Browder, FE: Convergence of approximation to fixed points of nonexpansive non-linear mappings in Hilbert spaces. Arch Rational Mech Anal. 24, 82-90 (1967)

21. Takahashi, W, Toyoda, M: Weak convergence theorems for nonexpansive mappings and monotone mappings. J Optim Theory Appl. 118, 417-428 (2003). doi:10.1023/A:1025407607560

22. Shimizu, T, Takahashi, W: Strong convergence to common fixed points of families of nonexpansive mappings. J Math Anal Appl. 211, 71-83 (1997). doi:10.1006/jmaa.1997.5398 
23. Geobel, K, Kirk, WA: Topics in Metric Fixed Point Theory. In Cambridge Studies in Advanced Mathematics, vol. 28, Cambridge University Press (1990)

doi:10.1186/1687-1812-2011-101

Cite this article as: Yao et al:: Hierarchical convergence of an implicit double-net algorithm for nonexpansive

semigroups and variational inequality problems. Fixed Point Theory and Applications 2011 2011:101.

Submit your manuscript to a SpringerOpen ${ }^{\odot}$ journal and benefit from:

- Convenient online submission

- Rigorous peer review

- Immediate publication on acceptance

- Open access: articles freely available online

- High visibility within the field

- Retaining the copyright to your article

Submit your next manuscript at $\boldsymbol{\nabla}$ springeropen.com 